\title{
EVALUASI TERHADAP KUALITAS PELAYANAN PUBLIK MELALUI KAJIAN INDEKS KEPUASAN MASYARAKAT (IKM) PADA UNIT REFERENSI PERPUSTAKAAN UNIVERSITAS GADJAH MADA Aprilia Mardiastuti *
}

\begin{abstract}
The problems discussed in this research are the quality of public services has been implemented by the Reference Unit Gadjah Mada University Library and the factors that need to be improve in order to improve the quality of service to the community. The purpose of this research was to determine the quality of public services that have been implemented by the Reference Unit Gadjah Mada University Library. The methods used to collect the data are survey and documentation. Research instrument that serves as a means of collecting data in this survey is a questionnaire filled in or is asked to each respondent, are about 14 elements, they are procedure, elements of services, clarity of service personnel, disciplinary officer, officer responsibilities, the ability of officers, fairness in obtaining service, politeness and friendliness of staff, service costs, the matches between service costs with the rule, the accuracy of the service schedule, environmental comfort, and the environmental safety. Methods of data analysis used in this study are based on the Minister for Administrative Reform No. KEP/25/M.PAN/2/2004 consist General Guidelines for Preparation of Community Satisfaction Index. The respondents were Diploma or Undergraduate Students, Postgraduate Student, Doctoral Programs Student, Lecturers/Researchers, and the public, and up to 150 respondents. Based on the results of a survey of 150 respondents, there are four elements of service that has a value less than 2.51 or not good, that is the procedure of service, speed of service, service costs, and environmental comfort. Elements that have values between 2.51 to 3.25 or have a good value, includes elements of compliance with the provisions of environmental safety and the matches between service costs with the rule. While the element that scored more than 3.26 or very well include elements of service requirements, clarity of service personnel, disciplinary officer, officer responsibilities, the ability of officers, fairness in obtaining service, politeness and friendliness of staff, as well as the accuracy of the service schedule. Based on the analysis of research data, overall, public services are maintained by the Reference Unit Gadjah Mada University Library has a service quality index value 77,225 or quality $B$, we can say that public service at the Reference Unit Gadjah Mada University Library is Good Enough.

Keywords:quality of public service, community satisfaction index, reference unit
\end{abstract}

* Pustakawan UGM

\section{A. PENDAHULUAN}

Tuntutan masyarakat mengenai perlu dilakukannya perbaikan kinerja birokrasi pelayanan publik telah menjadi wacana sampai saat ini. Maraknya isu demokratisasi telah menempatkan publik pada posisi yang kuat untuk menuntut hak-hak mereka ketika berhubungan dengan birokrasi pelayanan publik yang diberikan oleh penyedia layanan (Subarsono, 2006: 135). Para penyedia layanan dan mengharapkan adanya masukan atau kritik dari pemustaka layanan tentang produk yang dimanfaatkan oleh konsumen (Wicaksono, 2003: 1). Institusi penyelenggara layanan selalu dituntut dapat meningkatkan kualitas pelayanannya karena kualitas merupakan sasaran yang terus berubah. Suatu alat yang sekarang dianggap efektif, di waktu yang akan datang tidak memuaskan karena adanya inovasi teknologi sehingga perbaikan dan peningkatan perlu terus dilakukan (Hardjosoedarmo, 1996: 61).

Tuntutan itu tidak hanya berlaku bagi perusahaan saja, melainkan penting diterapkan pada perpustakaan sebagai penyedia dan penyelenggara pelayanan publik. Perpustakaan perlu berupaya melaksanakan tugasnya dengan sebaikbaiknya terutama dalam rangka menjalankan fungsinya, lebih mengedepankan pada pemberian pelayanan yang baik kepada 
pemustaka dengan memanfaatkan informasi dari pemustaka menyangkut kualitas kinerja pelayanan yang diberikan (Sulistyo-Basuki, 1994: 46).

Masalah sering dihadapi oleh. pemustaka apabila membutuhkan pelayanan, seperti, berbelit-belit, dibutuhkan waktu yang lama, biaya mahal dan kurangnya informasi mengenai persyaratan yang harus dipersiapkan (Sinaga, 2006). Kritik terhadap petugas pelayanan perpustakaan juga dilontarkan oleh beberapa pakar di bidang perpustakaan (Mudge dalam Trimo, 1997: 27). Untuk membantu memecahkan persoalan perpustakaan yang berkaitan dengan pelayanan publik tersebut perlu dilakukan suatu kajian untuk menyusun Indeks Kepuasan Masyarakat (IKM) pada unit pelayanan perpustakaan.

Tujuan dilakukannya evaluasi terhadap kualitas pelayanan publik melalui kajian (IKM) pada Unit Referensi Perpustakaan UGM adalah:

1. Mengetahui kualitas penyelenggaraan pelayanan publik yang telah dilaksanakan oleh Unit Referensi Perpustakaan UGM

2. Hasil IKM dapat digunakan sebagai bahan masukan dalam rangka meningkatkan kualitas pelayanan kepada masyarakat.

\section{B. TINJAUAN PUSTAKA}

Menurut Deming (dalam Hardjosoedarmo, 1996: 7-8) kualitas atau mutu merupakan suatu konsep yang sulit didefinisikan. Secara umum hanya dikatakan bahwa kualitas adalah karakteristik produk atau jasa yang ditentukan oleh pemakai atau customer dan diperoleh melalui pengukuran proses serta melalui perbaikan yang berkelanjutan. Kualitas tidak dapat didefinisikan apabila tidak dikaitkan dengan suatu konteks, persepsi customer, serta kebutuhan dan kemauan customer. Penilaian subjektif manusia terhadap produk atau jasa layanan dapat berubah-ubah karena suatu pengaruh misalnya iklan, reputasi produk atau jasa tertentu, pengalaman, teman dan sebagainya. Oleh karena sifat manusia akan kebutuhan dan kemauan yang tidak terbatas, serta persepsi yang selalu berubah terhadap suatu produk atau jasa layanan, maka kajian tentang kepuasan manusia terhadap suatu produk atau jasa layanan tersebut menjadi topik yang menarik untuk selalu dibahas.

Perpustakaan dalam perannya menyediakan dan melayankan segala informasi mempergunakan beberapa jasa, strategi, maupun berbagai cara untuk memuaskan pemustaka dalam menerima layanan. Namun di sisi lain, kepuasan selalu berhadapan dengan masalah keluhan walaupun pustakawan sudah semaksimal mungkin dalam memberikan jasa penyediaan informasi (Qalyubi, 2007: 203-206). Dengan demikian, perlu dilakukan berbagai langkah untuk mengetahui harapan dan kenyataan dalam pelayanan perpustakaan.

\section{Pengertian Evaluasi}

Dalam Kamus Besar Bahasa Indonesia, evaluasi berasal berarti penilaian. Dalam bidang manajemen, evaluasi dilakukan dengan maksud menilai pekerjaan seseorang dengan tujuan untuk menetapkan struktur penggajian dan peningkatan kualitas pekerjaan (Poels, 1997: 24).

Evaluasi dapat dipergunakan untuk penaksiran atau penilaian terhadap pertumbuhan dan kemajuan sebuah institusi ke arah tujuan atau nilai yang telah ditetapkan dalam tujuan institusi. Dengan demikian peranan dan fungsi evaluasi merupakan faktor yang sangat penting dalam proses perkembangan institusi tersebut.

\section{Kualitas Pelayanan Publik}

Secara teoritis, tujuan dari pelayanan publik pada dasarnya adalah memuaskan masyarakat (Sinambela, 2008: 6). Lebih jauh, Sinambela menjelaskan bahwa untuk mencapai kepuasan itu dituntut kualitas pelayanan prima yang tercermin dari transparansi, akuntabilitas, kondisional, partisipatif, kesamaan hak, dan keseimbangan antara hak dan kewajiban. Pelayanan perpustakaan dalam perannya menyediakan dan menyebarkan informasi menghadapi berbagai kategori informasi atau produk yang dihasilkän untuk dilayankan kepada konsumennya. Dalam memberikan strategi kepuasan pemakai perpustakaan terdapat tiga kunci utama sebagai berikut (Qalyubi, et.al., 2007: 204): 
1. Kemampuan memahami kebutuhan dan keinginan pemakai serta memahami tipe-tipe pemakai perpustakaan

2. Pengembangan database yang lebih akurat, termasuk data kebutuhan dan keinginan setiap segmen pemakai dan perubahan kondisi

3. Pemanfaatan informasi-informasi yang diperoleh dari riset pasar dalam suatu kerangka strategis

\section{Kualitas \\ Pelayanan \\ Referensi \\ Perpustakaan UGM Sebagai Pelayanan Publik}

Fungsi perpustakaan perguruan tinggi sebagai lembaga pelayanan publik adalah menyediakan pelayanan kepada pemustaka dengan berorientasi pada pasar (Hughes dalam Masruri, 2003: 157). Orientasi pasar yang dimaksudkan adalah adanya keseimbangan antara posisi penawaran supply) dengan permintaan (demand). Sebagai usaha untuk meningkatkan kualitas pelayanan, suatu perpustakaan perguruan tinggi harus memperhatikan dan meningkatkan komitmen dan kesadaran serta kemampuan karyawan atau staf, terutama bagi mereka yang berhubungan langsung dengan pemustaka (Masruri, 2003: 162).

Kualitas pelayanan referensi dapat dicapai dengan mengefektifkan kinerja layanan dalam memenuhi kebutuhan informasi dengan memperhatikan sumbersumber informasi dan orang-orang yang mengeksploitasi sumber-sumber informasi tersebut (Lestari, 2005: 13-17). Unit Referensi Perpustakaan UGM sebagai unit yang memberikan pelayanan kepada publik, mengutamakan kepuasan pelanggan customer satisfaction) dengan mengefektifkan kinerja pelayanan referensi dan efisiensi sumber daya yang dialokasikan dan dipergunakan untuk menyiapkan jasa pelayanan tersebut, untuk memaksimalkan kepuasan pemustaka dan meminimalkan waktu mereka, meningkatkan jumlah pemustaka, memberikan jawaban pertanyaan, serta menjadikan unit referensi sebagai tempat belajar dan melakukan riset-riset akademik (Program Kerja Bidang Pelayanan Pada Unit Referensi Perpustakaan UGM, 2009).
Pengertian Indeks Kepuasan Masyarakat (IKM)

Keputusan Menteri Pendayagunaan Aparatur Negara Nomor: KEP/25M.PAN/2/2004 Tanggal 24 Februari 2004, yang dimaksud dengan Indeks Kepuasan Masyarakat (IKM) adalah data dan informasi tentang tingkat kepuasan masyarakat yang diperoleh dari hasil pengukuran secara kuantitatif atas pendapat masyarakat dalam memperoleh pelayanan dari aparatur penyelenggara pelayanan publik dengan membandingkan antara harapan dan kebutuhannya.

Penyelenggara Pelayanan Publik adalah unit-unit pelayanan publik pada instansi pemerintah, dalam hal ini adalah Perpustakaan Universitas Gadjah Mada. Sedangkan Pemberi Pelayanan Publik atau aparatur penyelenggara pelayanan publik pada perpustakaan meliputi pustakawan dan karyawan yang ditugaskan di lembaga perpustakaan. Penerima Pelayanan Publik adalah pemustaka yang dilayani.

\section{METODE PENELITIAN}

Menurut Silverman (dalam Pendit, 2003: 163), metode penelitian adalah keseluruhan dari cara penelitian yang didasarkan pada pendekatan tertentu, sementara metode penelitian lebih merupakan rincian teknik-teknik yang dilakukan dalam suatu penelitian. Maka untuk mendapatkan karya ilmiah yang runtut, sistematis, dan benar digunakan metode tertentu. Agar penelitian yang akan dilaksanakan ini sistematis dan dapat dipertanggungjawabkan kebenarannya, akan diuraikan meliputi lokasi penelitian, subjek dan objek penelitian, populasi dan sampel penelitian, metode pengumpulan data dan instrumen, serta metode analisis data.

Lokasi penelitian ini dilakukan di Unit Referensi Perpustakaan UGM yang memberikan jasa layanan referensi kepada pemustaka, meliputi penelusuran literatur, rujukan cepat, bimbingan pemustaka, dan pelayanan fasilitas pendukung misalnya fotokopi, scan dokumen/gambar, dan ruang belajar/wifi area. subjek penelitian ini adalah seluruh sivitas akademika dan masyarakat 
luas yang menggunakan jasa pelayanan pada Unit Referensi Perpustakaan UGM, sedangkan yang menjadi objek penelitian adalah kualitas pelayanan pada Unit Referensi Perpustakaan UGM. Populasi daläm penelitian ini adalah semua penerima layanan pada Unit Referensi Perpustakaan UGM. Berdasarkan data statistik Bulan Januari sampai dengan Bulan Juni 2009, jumlah pengunjung pada Unit Referensi Perpustakaan UGM adalah 5748 pengunjung (Statistik Pelayanan Referensi Bulan Januari-Juni 2009).

Penentuan sampel dengan metode pengambilan secara aksidental (accsidental sample)., Responden dalam Kajian IKM adalah para penerima pelayanan dari Unit Referensi Perpustakaan UGM sebanyak 150 responden. Metode yang digunakan adalah metode survei menggunakan kuesioner atau pertanyaan tertutup berupa pilihan ganda. Dalam Indeks Kepuasan Masyarakat dikembangkan empat belas unsur yang akan diteliti, yaitu:

1. Prosedur pelayanan yaitu kemudahan tahapan pelayanan yang diberikan kepada masyarakat dilihat dari sisi kesederhanaan alur pelayanan ;

2. Prasyarat pelayanan yaitu persyaratan teknis dan administratif yang diperlukan untuk mendapatkan pelayanan sesuai dengan jenis pelayanan;

3. Kejelasan petugas pelayanan yaitu keberadaan dan kepastian petugas yang memberikan pelayanan (nama, jabatan serta kewenangan dan tanggungjawabnya);

4. Kedisiplinan petugas pelayanan yaitu kesungguhan petugas dalam memberikan pelayanan terutama terhadap konsistensi waktu kerja sesuai ketentuan yang berlaku ;

5. Tanggung jawab petugas pelayanan yaitu kejelasan wewenang dan tanggung jawab petugas dalam penyelenggaraan dan penyelesaian pelayanan;

6. Kemampuan petugas pelayanan yaitu tingkat keahlian dan keterampilan yang dimiliki petugas dalam memberikan/menyelesaikan

pelayanan;

7. Kecepatan pelayanan yaitu target waktu pelayanan dapat diselesaikan dalam waktu yang telah ditentukan oleh unit penyelenggara pelayanan;

8. Keadilan mendapatkan pelayanan yaitu pelaksanaan pelayanan dengan tidak membedakan golongan/status masyarakat yang dilayani ;

9. Kesopanan dan keramahan petugas yaitu sikap dan perilaku petugas dalam memberikan pelayanan kepada masyarakat secara sopan dan ramah serta saling menghargai dan menghormati ;

10. Kewajaran biaya pelayanan yaitu keterjangkauan masyarakat terhadap besarnya biaya yang ditetapkan oleh unit pelayanan;

11. Kepastian biaya pelayanan yaitu kesesuaian antara biaya yang dibayarkan dengan biaya yang telah ditetapkan ;

12. Kepastian jadwal pelayanan yaitu pelaksanaan waktu pelayanan, sesuai dengan ketentuan yang telah ditetapkan ;

13. Kenyamanan lingkungan yaitu kondisi sarana dan prasarana pelayanan yang bersih, rapi, dan teratur sehingga dapat memberikan rasa nyaman

14. Keamanan pelayanan yaitu terjaminnya tingkat keamanan lingkungan unit penyelenggara pelayanan ataupun sarana yang digunakan.

Untuk memberikan deskripsi mengenai subjek penelitian berdasarkan data yang diperoleh dari subjek yang diteliti, dilakukan analisis deskriptif yang berupa frekuensi dan persentase. Penyajian frekuensi dan persentase dapat memberikan gambaran mengenai distribusi subjek yang diteliti sehingga pembaca akan dengan mudah memahami hasil penelitian (Azwar, 2009: 126). Persentase diperoleh dengan rumus berikut:

$$
\mathrm{P}=\frac{\mathrm{f}}{100 \%}
$$

$\mathrm{P}=$ Prosentase $; \mathrm{f}=$ frekuensi jawaban 
Berdasarkan skala likert empat poin maka dibuat kategorikal untuk menentukan range dari masing-masing unsur pelayanan dan tingkat kepuasan sebagai langkah interpretasi rata-rata statistik (mean) dari seluruh jawaban responden penelitian sebagai berikut:

1. nilai $1-1,50$ dikategorikan sebagai statistic mean dari jawaban $\mathrm{A}$;

2. nilai $1,51-2,50$ dikategorikan sebagai statistic mean dari jawaban $\mathrm{B}$;

3. nilai 2,51-3,50 dikategorikan sebagai statistic mean dari jawaban $C$;

4. nilai 3,51-4,00 dikategorikan sebagai statistic mean dari jawaban D.

Penyusunan IKM dilakukan dengan bantuan program Microsoft Excel dengan prosedur perhitungan sesuai dengan pedoman umum (IKM).

Data hasil kuesioner setelah diskoring, kemudian direkap dan diolah berdasarkan pedoman umum IKM. Nilai masing-masing unsur pelayanan dijumlahkan sesuai dengan jumlah kuesioner yang diisi oleh responden. Kemudian untuk mendapatkan nilai rata-rata per unsur pelayanan dengan cara jumlah nilai masing-masing unsur pelayanan dibagi dengan jumlah responden.

Penghitungan IKM terhadap 14 unsur pelayanan yang dikaji, setiap unsur pelayanan memiliki penimbang yang sama, yaitu 0,071 . Nilai ini diperoleh dengan rumus berikut:

\begin{tabular}{lllll}
\hline 1 & $1,00-1,75$ & $25,00-43,75$ & D & Sangat tidak baik \\
\hline 2 & $1,76-2,50$ & $43,76-62,50$ & C & Tidak Baik \\
\hline 3 & $2,51-3,25$ & $62,51-81,25$ & B & Baik \\
\hline 4 & $3,26-4,00$ & $81,26-100,00$ & A & Sangat Baik \\
\hline
\end{tabular}

Bobot nilai rata-rata tertimbang $=\frac{1}{14}=0,071$

1 = jumlah bobot tiap unsur dalam IKM; $14=$ jumlah unsur dalam IKM

Untuk menentukan nilai IKM diperoleh dengan cara menjumlahkan nilai rata-rata per unsur pelayanan yang telah dikalikan dengan bobot nilai rata-rata tertimbang. Bila dijabarkan dalam rumus, adalah sebagai berikut:

\section{Total nila i per unsur \\ IKM = - -..-- $\quad x$ Bobot \\ Nilai Rata-Rata Tertimbang unsur yang terisi}

Untuk memudahkan intepretasi terhadap nilai IKM yaitu antara $25-100$ maka hasil penilaian di atas dikonversikan dengan nilai dasar 25 dengan rumus sebagai berikut:

\section{IKM unit pelayanan $x 25$}

Total nilai per unsur diperoleh dengan menjumlah nilai masing-masing unsur pelayanan sesuai dengan jumlah responden yang mengisi. Unsur yang terisi diperoleh dari jumlah total responden yang mengisi kuesioner. Sedangkan Bobot Nilai Rata-Rata Tertimbang adalah 0,071 yang diperoleh dari jumlah bobot tiap unsur (1) dibagi dengan jumlah unsur dalam IKM (14).

Kategori persepsi nilai dapat dilihat pada tabel Nilai Persepsi, Interval IKM, Interval Konversi IKM, Mutu Pelayanan dan Kinerja Pelayanan sebagai berikut:

Tabel 1Nilai Persepsi, Interval IKM, Interval Konversi IKM,Mutu Pelayanan dan Kualitas 
Diploma/S1 atau 56,00\%, 'kategori Mahasiswa S2 sebanyak 27 orang atau $18,00 \%$, kategori Mahasiswa S3 sebanyak 15 orang atau $10,00 \%$, kategori Dosen/Peneliti sebanyak 14 orang atau $9,33 \%$, dan kategori Umum sebanyak 10 orang atau $6,64 \%$. Kategori Pemustaka juga dapat dilihat dalam tabel berikut:

Tabel 2

Kategori Pemustaka

\begin{tabular}{clrc}
\hline No. & Kategori & Jumlah & $\begin{array}{c}\text { Persen- } \\
\text { tase }\end{array}$ \\
\hline 1 & $\begin{array}{l}\text { Mahasiswa } \\
\text { Diploma/S1 }\end{array}$ & 84 responden & $56,00 \%$ \\
\hline 2 & Mahasiswa S2 & 27 responden & $18,00 \%$ \\
\hline 3 & Mahasiswa S3 & 15 responden & $10,00 \%$ \\
\hline 4 & Dosen/Peneliti & 14 responden & $9,33 \%$ \\
\hline 5 & Umum & 10 responden & $6,64 \%$ \\
\hline & Jumlah & 150 & 100,00 \\
& & responden & $\%$ \\
\hline
\end{tabular}

Sumber Data Primer yang diolah, 2009.

Kuesioner sebanyak 150 diolah dengan cara memberi nomor responden, kemudian memberikan skor jawaban responden sesuai dengan jawaban tiap butir pertanyaan. Masing-masing kuesioner kemudian diolah dengan cara memasukkan skor jawaban ke dalam Formulir Pengolahan (IKM) Per Responden, mulai dari kolom U1 sampai U14 untuk masing-masing responden. Skor 1 diberikan jika responden memberikan jawaban a, skor 2 untuk jawaban b, skor 3 untuk jawaban c, dan skor 4 untuk jawaban d. Sedangkan skor 0 diberikan untuk pertanyaan yang tidak dijawab. Frekuensi jawaban diisi dengan jumlah responden yang menjawab, sedangkan nilai per unsur diisi dengan frekuensi jawaban dikalikan skor. Persentase responden merupakan jumlah persentase dari total jumlah responden sebanyak 150 orang.

Setelah melalui proses pengolahan data, diperoleh nilai rata-rata per unsur pelayanan yang akan disajikan dalam Tabel Data Per Unsur Pelayanan. Berdasarkan hasil analisis data untuk menentukan (IKM) terhadap 14 unsur penilaian pada Unit Referensi Perpustakaan UGM, maka diperoleh hasil nilai unsur pelayanan dan nilai rata-rata per unsur pelayanan seperti pada tabel 3 berikut:

Tabel 3

Nilai Unsur Pelayanan Dan Nilai Rata-Rata Per Unsur Pelayanan

\begin{tabular}{|c|c|c|c|}
\hline No. & Unsur Pelayanan & $\begin{array}{l}\text { Nilai Unsur } \\
\text { Pelayanan }\end{array}$ & Persepsi Nilai \\
\hline 1 & Prosedur pelayanan & 2,12 & Tidak Mudah \\
\hline 2 & Persyaratan Pelayanan & 3,43 & Sangat Sesuai \\
\hline 3 & Kejelasan Petugas Pelayanan & 3,55 & Sangat Jelas \\
\hline 4 & Kedisiplinan Petugas Pelayanan & 3,51 & Sangat Disiplin \\
\hline 5 & Tanggung Jawab Petugas Pelayanan & 3,67 & Sangat Tanggung Jawab \\
\hline 6 & Kemampuan Petugas Pelayanan & 3,53 & Sangat Mampu \\
\hline 7 & Kecepatan Pelayanan & 2,33 & Tidak Cepat \\
\hline 8 & Keadilan Mendapatkan Pelayanan & 3,49 & Sangat Adil \\
\hline 9 & Kesopanan Dan Keramahan Petugas & 3,81 & Sangat Sopan/Ramah \\
\hline 10 & Kewajaran Biaya Pelayanan & 2,05 & Tidak Wajar \\
\hline 11 & Kesesuaian Biaya Dengan Ketentuan & 3,19 & Sesuai \\
\hline 12 & Ketepatan Jadwal Pelayanan & 3,41 & Sangat Tepat \\
\hline 13 & Kenyamanan Lingkungan & 2,28 & Tidak Nyaman \\
\hline 14 & Keamanan Lingkungan Pelayanan & 3,15 & Aman \\
\hline
\end{tabular}

Sumber Data Primer yang diolah, 2009.

Sumber Data Primer yang diolah, 2009. 
Nilai Indeks Kepuasan Masyarákat (IKM) Unit Pelayanan

Indeks pelayanan pada Unit Referensi Perpustakaan UGM adalah sebagai berikut: $(2,12 \times 0,071)+(3,43 \times 0,071)+(3,55 \times$ $0,071)+(3,51 \times 0,071)+(3,67 \times 0,071)+$ $(3,53 \times 0,071)+(2,33 \times 0,071)+(3,49 \times$ $0,071)+(3,81 \times 0,071)+(2,05 \times 0,071)+$ $(3,19 \times 0,071)+(3,41 \times 0,071)+(2,28 \times$ $0,071)+(3,15 \times 0,071)=3,089$ (nilai indeks)

\section{Konversi Nilai Indeks Kepuasan Masyarakat (IKM) \\ Intepretasi terhadap nilai IKM yaitu} antara $25-100$, sehingga hasil Nilai Indeks Kepuasan Masyarakat (IKM) Unit Pelayanan di atas dikonversikan dengan nilai dasar 25, sebagai berikut: $3,089 \times 25=77,225$

\section{Tingkat Kualitas Pelayanan}

Berdasarkan konversi nilai (IKM), maka tingkat kualitas pelayanan pada Unit Referensi Perpustakaan UGM yang merupakan hasil akhir dari IKM adalah sebagai berikut:

$\begin{array}{ll}\text { Mutu Pelayanan } & =\text { B } \\ \text { Kualitas Unit Pelayanan } & =\text { Baik }\end{array}$

\section{KESIMPULAN}

Berdasarkan analisis data hasil penelitian dapat diambil beberapa simpulan sebagai berikut:

1. Pelayanan publik yang diselenggarakan oleh Unit Referensi Perpustakaan UGM secara keseluruhan mendapatkan nilai indeks 77,225 atau mutu pelayanan $B$, dengan tingkat kualitas pelayanan Baik.

2. Ada empat unsur pelayanan yang mendapatkan nilai unsur pelayanan kurang dari 2,51 atau tidak baik, yaitu prosedur pelayanan mendapatkan nilai indeks 2,12, kecepatan pelayanan mendapatkan nilai indeks 2,31 , biaya pelayanan mendapatkan nilai indeks 2,05, dan kenyamanan lingkungan mendapatkan nilai indeks 2,28 .

3. Unsur yang mendapatkan nilai antara 2,51 - 3,25 atau baik meliputi unsur kesesuaian biaya pelayanan dengan ketentuan mendapatkan nilai indeks
3,19, serta keamanan lingkungan pelayanan dengan nilai indeks 3,15 .

4. Sedangkan unsur yang mendapatkan nilai lebih dari 3,26 atau sangat baik meliputi unsur persyaratan pelayanan mendapatkan nilai indeks 3,43 , kejelasan petugas pelayanan mendapatkan nilai indeks 3,55, kedisiplinan petugas mendapatkan nilai indeks 3,51, tanggung jawab petugas mendapatkan nilai indeks 3,67, kemampuan petugas mendapatkan nilai indeks 3,53, keadilan dalam mendapatkan pelayanan mendapatkan nilai indeks 3,49, kesopanan dan keramahan petugas mendapatkan nilai indeks 3,81 , serta ketepatan jadwal pelayanan mendapatkan nilai indeks 3,41.

5. Faktor-faktor yang perlu diperbaiki dalam rangka meningkatkan kualitas pelayanan meliputi unsur prosedur pelayanan, kecepatan pelayanan, biaya pelayanan, dan kenyamanan lingkungan

\section{DAFTAR PUSTAKA}

Azwar, Saifuddin, 2009. Metode Penelitian. Yogyakarta: Pustaka Pelajar

Hardjosoedarmo, Soewarso, 1996. DasarDasar Total Quality Management. Yogyakarta: Penerbit Andi

Indonesia. Kementrian Pendayagunaan Aparatur Negara, 2004. Keputusan Menteri Pendayagunaan Aparatur Negara Nomor KEP/25/M.PAN /2/2004 tentang Pedoman Umum Penyusunan Indeks Kepuasan Masyarakat Unit Pelayanan Instansi Pemerintah. Jakarta: Kementrian Pendayagunaan Aparatur Negara Republik Indonesia

Lestari M., Tri, 2005. "Kinerja Layanan Rujukan Pada UPT Perpustakaan Universitas Jember: Studi Kasus Di UPT Perpustakaan Universitas Jember" dalam Berkala Ilmu Perpustakaan Dan Informasi Vol. II, No. 2

Masruri, Anis, 2003. "Kualitas Pelayanan Perpustakaan Perguruan Tinggi Sebagai Pelayanan Publik" dalam 
Thaqafiyyat, Jurnal 'Bahasa, Peradaban, Dan Informasi Islam Vol. 4, No. 2, Juli - Desember

Pendit, Putu Laxman, 2003. Penelitian Ilmu Perpustakaan Dan Informasi: Suatu Pengantar Diskusi Epistemologi Dan Metodologi. Jakarta: Jurusan Ilmu Perpustakaan-Fakultas Sastra Universitas Indonesia

Perpustakaan Universitas Gadjah Mada, 2009. Statistik Pemakai Layanan Pada Unit Referensi, Bulan Januari - Juni 2009. Yogyakarta: Unit Referensi Perpustakaan UGM

Poels, Frans, 1997. Strategi Evaluasi Kerja Dan Renumerasi: Bagaimana Merancang Dan Menjalankan Sistem Yang Efektif (Seri The Art Of HRD). Jakarta: Bhuana Ilmu Populer

Qalyubi, Syihabuddin, et.al., 2007. Dasardasar Ilmu Perpustakaan dan Informasi. Yogyakarta: Jurusan Ilmu Perpustakaan dan Informasi Fakultas Adab

Sinaga, Saroha, 2006. "Pelayanan Perpustakaan Terlalu Birokratis" dalam Kedaulatan Rakyat Online tanggal 20 Juli 2006, www.kr.co.id, diakses 8 Mei 2009 pukul 11.15 WIB
Sinambela, Lijan Poltak, 2008. Reformasi Pelayanan Publik: Teori, Kebijakan, Dan Implementasi.Jakarta : Bumi Aksara

Subarsono, A.G., 2006. "Pelayanan Publik Yang Efisien, Responsif, Dan NonPartisan" dalam Mewujudkan Good Governance Melalui Pelayanan Publik. Yogyakarta: Gadjah Mada University Press

Sulistyo-Basuki, 1994, Pengantar Ilmu Perpustakaan. Jakarta: Gramedia Pustaka Utama

Trimo, Soejono, 1997. Reference Work Dan Bibliography: Buku Panduan Dengan Sistem Modular. Jakarta: Bumi Aksara

Wicaksono, Bambang, 2003, Survey Pelanggan: Upaya Mendekatkan diri Pada Pengguna Layanan. Yogyakarta: Pusat Studi Kependudukan dan Kebijakan Universitas Gadjah Mada 